Journal of Healthcare Technology and Medicine Vol. 6 No. 1 April 2020

Universitas Ubudiyah Indonesia

e-ISSN : $261109 x$

\title{
Hubungan Jarak Kelahiran Dan Berat Bayi Lahir Dengan Kejadian Ruptur Perineum Pada Persalinan Normal Di Rsu Tgk Chik Ditiro Tahun 2019
}

\section{Relationship Of Birth Distance And Weight Of Birth With The Event Of The Rupture Perineum In Labor Normal In Rsud Tgk Chik Ditiro Sigli}

Pidie District

\author{
Juliati, ${ }^{1}$ Zulfa Riskina ${ }^{2}$, Cut Afra Riska ${ }^{3}$ \\ Emial: juliatiinfo@gmail.com*1 \\ Dosen Akbid Darul Husada ${ }^{1,2,3}$
}

\begin{abstract}
ABSTRAK
Ruptur perineum terjadi pada hampir semua persalinan pertama dan tidak jarang terjadi pada persalinan berikutnya. Jenis penelitian deskriptif analitik dengan penelitian kuantitatif. Jenis studi korelasional, meneliti pengaruh variabel secara retrospektif, yaitu melakukan penelitian terhadap data yang terjadi di masa lalu. Penelitian dilakukan tanggal 28 Oktober sampai 5 November 2019 di RSUD Tgk Chik Di Tiro Sigli. Populasi penelitian ini seluruh wanita persalinan normal di Ruang Kebidanan berjumlah 97 orang. Sampel dalam penelitian menggunakan teknik total populasi 97 orang. Hasil penelitian menunjukkan mayoritas responden berada pada kategori jarak kelahiran $<2$ tahun sebanyak 53 responden (54,6\%). Mayoritas berat badan lahir bayi yang lahir berada pada kategori berat lahir> 2500-4000 gram sebanyak 43 responden (44,3\%). Hasil penelitian, dari hasil uji bivariat $\mathrm{P}$-value $=0,005$ terdapat hubungan jarak lahir dengan kejadian ruptur perineum, dan berat badan lahir.
\end{abstract}

\section{ABSTRACT}

Perineal rupture occurs in nearly all first deliveries and is not uncommon with subsequent deliveries. This type of descriptive analytic research with quantitative research. This type of correlational study examines the effect of variables retrospectively, which is conducting research on past data. The study was conducted from 28 October to 5 November 2019 at the Tgk Chik Di Tiro Sigli Regional Hospital. The population of this study were all women with normal delivery in the midwifery room totaling 97 people. The sample in this study used a total population technique of 97 people. The results showed that the majority of respondents were in the category of birth spacing <2 years as many as 53 respondents (54.6\%). The majority of birth weight babies born were in the category of birth weight> 2500-4000 grams as many as 43 respondents (44.3\%). The results of the study, from the results of the bivariate test $P$-value = 0.005 , there was a relationship between birth distance and the incidence of perineal rupture and birth weight. 
Journal of Healthcare Technology and Medicine Vol. 6 No. 1 April 2020

Universitas Ubudiyah Indonesia

e-ISSN : 261109X

\section{PENDAHULUAN}

Persalinan sering mengakibatkan perlukaan jalan lahir, luka biasanya ringan tetapi kadangkadang terjadi luka yang luas dan berbahaya. Setelah persalinan harus selalu dilakukan pemeriksaan vulva dan perineum. Ruptur perineum terjadi pada hampir semua persalinan pertama dan tidak jarang juga terjadi pada persalinan berikutnya (Wiknjosastro.,2016). Ruptur biasanya ringan tetapi kadang terjadi juga luka yang luas dan berbahaya, yang menyebabkan perdarahan banyak. Perdarahan post partum menjadi penyebab utama sebesar $40 \%$ kematian ibu di Indonesia. Angka kejadian perdarahan karena ruptur perineum sekitar 4-5\%. Perdarahan postpartum merupakan salah satu masalah penting karena berhubungan dengan kesehatan ibu yang dapat menyebabkan kematian (Dina dkk, 2013).

Ruptur perineum merupakan terjadinya perlukaan (robek) pada otot perineum selama proses persalinan kala II dan dapat berulang pada persalinan berikutnya. Perlukaan pada perineum umumnya terjadi di garis tengah dan bisa meluas bila persalinan teralu cepat dan ukuran bayi yang semakin besar (Prawitasari dkk,2015). Akibat langsung dari ruptur perineum adalah dapat terjadi perdarahan. Kesalahan dalam menjahit akan menimbulkan inkontinensia alvi (proses defekasi yang tidak dapat ditahan) karena sfingterani tidak terjahit dengan sempurna, fistula rektovagina, introitus vagina menjadi longgar sehingga akan menimbulkan keluhan dalam hubungan seksual (Manuaba, 2010).

Jumlah kasus kematian Bayi turun dari 33.278 di tahun 2015 menjadi 32.007 pada tahun 2016, dan di tahun 2017 di semester I sebanyak 10.294 kasus. Demikian pula dengan angka kematian Ibu turun dari 4.999 tahun 2015 menjadi 4912 di tahun 2016 dan di tahun 2017 (semester I) sebanyak 1712 kasusKemenkes RI, 2017). Penyebab tingginya AKI di Indonesia adalah perdarahan, hipertensi, infeksi, dan penyebab lain (Kemenkes, 2017).

Penelitian di lakukan di RSUD Tgk Chik Di Tiro, data yang diperoleh dari Rekam Medis RSUD Tgk Chik Di Tiro dari bulan Januari-Juli 2018 terdapat 225 orang ibu bersalin normal. Sedangkan ibu bersalin normal yang mengalami rupture perineum dari bulan Januari-Juli 2018 terdapat 97 orang. 
Journal of Healthcare Technology and Medicine Vol. 6 No. 1 April 2020

Universitas Ubudiyah Indonesia

e-ISSN : 261109X

\section{METODE PENELITIAN}

Desain yang digunakan adalah deskriptif analitik dengan jenis penelitian kuantitatif studi korelasional, mengkaji pengaruh antara variabel secara retrospektif yaitu melakukan penelitian terhadap data yang terjadi pada waktu lampau. Penelitian ini sudah dilakukan di rekam medik RSUD Tgk Chik Di Tiro Kabupaten Pidie pada tanggal 28 Oktober sampai 05 November 2019. Populasi dalam penelitian ini adalah seluruh ibu yang bersalin normal mengalami ruptur perineum yang tercatat di buku register ruang kebidanan RSUD Tgk Chik Di Tiro Kabupaten Pidie dari bulan Januari sampai Juli sebanyak 97 orang dan tekhnik pengambilan sampel yaitu total populasi. Pengumpulan data dilakukan dengan data primer dan data sekunder.

\section{HASIL DAN PEMBAHASAN}

\begin{tabular}{|c|c|c|c|c|c|c|c|c|}
\hline \multirow[b]{2}{*}{ No } & \multirow{3}{*}{$\begin{array}{c}\text { Jarak } \\
\text { Kelahira }\end{array}$} & \multicolumn{5}{|c|}{ Rupture Perineum } & \multirow[b]{2}{*}{ Total } & \multirow{2}{*}{$\begin{array}{c}\mathbf{P} \\
\text { Valu }\end{array}$} \\
\hline & & Derajat I & Derajat II & Derajat III & Derajat & Tidak & & \\
\hline & & & & & IV & Rupture & & $\mathbf{e}$ \\
\hline
\end{tabular}

1. Hubungan Jarak Kelahiran Dengan Kejadian Ruptur Perineum Pada Persalinan Normal

TABEL 1

HUBUNGAN JARAK KELAHIRAN DENGAN KEJADIAN RUPTUR PERINEUM

PADA PERSALINAN NORMAL DI RSU TGK CHIK DITIRO TAHUN 2019 
Journal of Healthcare Technology and Medicine Vol. 6 No. 1 April 2020

Universitas Ubudiyah Indonesia

e-ISSN : 261109X

\begin{tabular}{|c|c|c|c|c|c|c|c|c|c|c|c|c|c|c|}
\hline & $\mathbf{n}$ & $\mathrm{F}$ & $\%$ & $\mathrm{~F}$ & $\%$ & $\mathrm{~F}$ & $\%$ & $\mathrm{~F}$ & $\%$ & $\mathrm{~F}$ & $\%$ & $\mathrm{~F}$ & $\%$ & \multirow{4}{*}{0,005} \\
\hline 1 & $<2$ tahun & 21 & 39,6 & 11 & 20,8 & 4 & 7,5 & 8 & 15,1 & 9 & 17,0 & 53 & 100 & \\
\hline 2 & $>2$ tahun & 17 & 38,6 & 19 & 43,2 & 6 & 13,6 & 0 & 0 & 2 & 4,5 & 44 & 100 & \\
\hline & Jumlah & 38 & & 30 & & 10 & & 8 & & 11 & & 97 & 100 & \\
\hline
\end{tabular}

Rupture Perineum

\begin{tabular}{lllllll}
\cline { 3 - 4 } No Jarak & Derajat I & Derajat II & Derajat III & Derajat & Tidak & Total Valu
\end{tabular}

Kelahira IV Rupture e

\begin{tabular}{|c|c|c|c|c|c|c|c|c|c|c|c|c|c|}
\hline & $\mathbf{n}$ & $\mathrm{F}$ & $\%$ & $\mathrm{~F}$ & $\%$ & $\mathrm{~F}$ & $\%$ & $\mathrm{~F}$ & $\%$ & $\mathrm{~F}$ & $\%$ & $\mathrm{~F}$ & $\%$ \\
\hline 1 & $<2$ tahun & 21 & 39,6 & 11 & 20,8 & 4 & 7,5 & 8 & 15,1 & 9 & 17,0 & 53 & 100 \\
\hline 2 & $>2$ tahun & 17 & 38,6 & 19 & 43,2 & 6 & 13,6 & 0 & 0 & 2 & 4,5 & 44 & 100 \\
\hline
\end{tabular}

Sumber : Data Primer (diolah tahun 2019)

Hasil analisa statistic menggunakan uji Chi-Square dengan nilai $\mathrm{P}$ value $=0,005<$ 0,03 hal tersebut berarti Ho ditolak dan Ha diterima, maka Ada Hubungan antara Jarak Kelahiran Dengan Kejadian Ruptur Perineum Pada Persalinan Normal di RSUD Tgk Chik Ditiro Sigli.

2. Hubungan Berat Bayi Lahir Dengan Kejadian Ruptur Perineum Pada Persalinan Normal

TABEL 2

HUBUNGAN BERAT BAYI LAHIR DENGAN KEJADIAN RUPTUR PERINEUM

PADA PERSALINAN NORMAL DI RSU TGK CHIK DITIRO TAHUN 2019 
Journal of Healthcare Technology and Medicine Vol. 6 No. 1 April 2020

Universitas Ubudiyah Indonesia

e-ISSN : 261109X

Jumlah

38

30

10

8

11

$97 \quad 100$

Sumber : Data Primer (diolah tahun 2019)

Hasil analisa statistic menggunakan uji Chi-Square dengan nilai P value $=0,001<$ 0,05 hal tersebut berarti Ho ditolak dan Ha diterima, maka Ada Hubungan antara Berat Bayi Lahir Dengan Kejadian Ruptur Perineum Pada Persalinan Normal di RSUD Tgk Chik Ditiro Sigli.

\section{PEMBAHASAN}

Dibawah ini dijelaskan hasil penelitian yang dilakukan dengan menggunakan analisa tentang Hubungan Jarak Kelahiran Dan Berat Bayi Lahir Dengan Kejadian Ruptur Perineum Pada Persalinan Normal di RSUD Tgk Chik Di Tiro Sigli Kabupaten Pidie, yang dianalisa dengan menggunakan uji Chi_Square test. Untuk lebih jelasnya dapat diperhatikan penjelasan pervariabel yaitu sebagai berikut:

1. Analisa Univariat

a. Jarak Kelahiran

Berdasarkan Tabel 5.2 menunjukkan bahwa dari 97 responden, mayoritas dengan jarak kelahiran < 2 tahun. Yaitu sebanyak 53 responden $(54,6 \%)$.

Menurut asumsi peneliti jarak kelahiran merupakan rentang waktu antara anak sekarang dengan anak sebelumnya. ibu bersalin dengan jarak kelahiran $<$ dari 2 tahun lebih cenderung mengalami komplikasi dibandingkan pada ibu bersalin dengan jarak > 2 tahun hal ini disebabkan karena organ-organ reproduksi ibu belum kembali pulih pada kondisi semula sebelum ibu hamil dan belum siap untuk proses kelahiran tetapi sudah harus melahirkan kembali.

Jarak kelahiran adalah rentang waktu antara kelahiran anak sekarang dengan kelahiran anak sebelumnya. DepKes (2007), menyatakan bahwa jarak kelahiran kurang dari dua tahun tergolong risiko tinggi karena dapat menimbulkan komplikasi ruptur perineum pada persalinan. Jarak kelahiran 2-3 tahun merupakan jarak kelahiran yang lebih aman bagi ibu dan janin.

b. Berat Bayi Lahir 
Journal of Healthcare Technology and Medicine Vol. 6 No. 1 April 2020

Universitas Ubudiyah Indonesia

e-ISSN : 261109X

Berdasarkan Tabel 5.3 menunjukkan bahwa dari 97 responden, mayoritas dengan berat bayi lahir > 2500-4000 gram. Yaitu sebanyak 43 responden (44,3\%).

Menurut asumsi peneliti berat bayi lahir yaitu berat badan bayi yang ditimbang sesaat setelah bayi dilahirkan. Semakin besar bayi yang dilahirkan meningkatkan resiko terjadinya ruptur perineum. Berat bayi lahir ditimbang dalam waktu satu jam sesudah lahir.Menurut Wafi Nur Muslihatun (2010) berat badan bayi lahir adalah berat badan neonatus pada saat kelahiran, ditimbang dalam waktu satu jam sesudah lahir.

Hubungan antara berat lahir dengan umur kehamilan, berat bayi lahir dapat dikelompokan : bayi kurang bulan (BKB), yaitu bayi yang dilahirkan dengan masa gestasi < 37 minggu (259 hari). Bayi cukup bulan (BCB), bayi yang dilahirkan dengan masa gestasi antara 37-42 minggu (259 - 293 hari), dan Bayi lebih bulan (BLB), bayi yang dilahirkan dengan masa gestasi > 42 minggu (294 hari) (Kosim dkk, 2009).

c. Ruptur Perineum

Berdasarkan Tabel 5.4 menunjukkan bahwa dari 97 responden, mayoritas mengalami rupture perineum derajat I. Yaitu sebanyak 38 responden $(39,2 \%)$.

Menurut asumsi peneliti ruptur adalah robekan atau koyaknya jaringan secara paksa sedangkan perineum adalah bagian yang terletak antara vulva dan anus. Jadi ruptur perineum adalah robekan pada jaringan yang terletak antara vulva dan anus yang terjadi pada saat persalinan. rupture perineum merupakan luka pada perineum yang terjadi karena sebab-sebab tertentu tanpa dilakukan tindakan perobekan disengaja. Ruptur adalah luka pada perineum yang diakibatkan oleh rusaknya jaringan secara alamiah karena proses desakan kepala janin atau bahu pada saat persalinan. Bentuk ruptur biasanya tidak teratur sehingga jaringan yang robek sulit dilakukan penjahitan (Sukrisno, Adi 2010).

\section{Analisa Bivariat}

a. Hubungan Jarak Kelahiran Dengan Kejadian Ruptur Perineum Pada Persalinan Normal

Berdasarkan Tabel 5.5 diatas menunjukkan bahwa dari 53 responden dengan jarak kelahiran $<2$ tahun mengalami ruptur perineum derajat I sebanyak 21 responden 
Journal of Healthcare Technology and Medicine Vol. 6 No. 1 April 2020

Universitas Ubudiyah Indonesia

e-ISSN : 261109X

$(39,6 \%)$, ruptur perineum derajat II sebanyak 11 responden $(20,8 \%)$, ruptur perineum derajat III sebanyak 4 responden (7,5\%), ruptur perineum derajat IV sebanyak 8 responden $(1,5 \%)$, tidak mengalami ruptur perineum sebanyak 9 responden $(17,0 \%)$, dan dari 44 responden dengan jarak kelahiran $>2$ tahun mengalami ruptur perineum derajat I sebanyak 17 responden $(38,6 \%)$, ruptur perineum derajat II sebanyak 19 responden $(43,2 \%)$, ruptur perineum derajat III sebanyak 6 responden $(13,6 \%)$, tidak mengalami ruptur perineum sebanyak 2 responden $(4,5 \%)$ Hasil analisa statistic menggunakan uji Chi-Square dengan nilai $\mathrm{P}$ value $=0,005<0,03$ hal tersebut berarti Ho ditolak dan Ha diterima, maka Ada Hubungan antara Jarak Kelahiran Dengan Kejadian Ruptur Perineum Pada Persalinan Normal di RSUD Tgk Chik Ditiro Sigli.

Jarak kelahiran adalah rentang waktu antara kelahiran anak sekarang dengan kelahiran anak sebelumnya. Jarak kelahiran kurang dari dua tahun tergolong resiko tinggi karena dapat menimbulkan komplikasi pada persalinan. Jarak kelahiran 2-3 tahun merupakan jarak kelahiran yang lebih aman bagi ibu dan janin. Begitu juga dengan keadaan jalan lahir yang mungkin pada persalinan terdahulu mengalami robekan perineum derajat tiga dan empat, sehingga proses pemulihan belum sempurna dan robekan perineum dapat terjadi (Depkes dalam Rosdiana, 2013).

Menurut pendapat ambarwati jarak kehamilan sebaiknya lebih dari 2 tahun. Jarak kahamilan yang terlalu dekat menyebabkan ibu punya kembali kondisi sebelumnya (Ambarawati dalam Rifida, 2012).

b. Hubungan Berat Bayi Lahir Dengan Kejadian Ruptur Perineum Pada Persalinan Normal

Berdasarkan Tabel 5.6 diatas menunjukkan bahwa dari 16 responden dengan berat bayi lahir > 2500 gram mengalami ruptur perineum derajat I sebanyak 11 responden $(68,8 \%)$, ruptur perineum derajat II sebanyak 3 responden $(18,8 \%)$, tidak mengalami ruptur perineum sebanyak 2 responden (12,5\%), dari 43 responden dengan berat bayi lahir 2500 - 4000 gram gram mengalami ruptur perineum derajat I sebanyak 22 responden $(51,2 \%)$, ruptur perineum derajat II sebanyak 10 responden $(23,3 \%)$, ruptur perineum derajat III sebanyak 2 responden (4,7\%), ruptur perineum derajat IV sebanyak 3 responden (7,0\%), tidak mengalami ruptur perineum sebanyak 6 responden 
Journal of Healthcare Technology and Medicine Vol. 6 No. 1 April 2020

Universitas Ubudiyah Indonesia

e-ISSN : 261109X

$(14,0 \%)$, dan dari 38 responden dengan berat bayi lahir > 4000 gram gram mengalami ruptur perineum derajat I sebanyak 5 responden $(13,2 \%)$, ruptur perineum derajat II sebanyak 17 responden $(44,7 \%)$, ruptur perineum derajat III sebanyak 8 responden $(21,1 \%)$, ruptur perineum derajat IV sebanyak 5 responden $(13,2 \%)$, tidak mengalami ruptur perineum sebanyak 3 responden $(7,9 \%)$

Hasil analisa statistic menggunakan uji Chi-Square dengan nilai $\mathrm{P}$ value $=$ 0,001 < 0,05 hal tersebut berarti Ho ditolak dan Ha diterima, maka Ada Hubungan antara Berat Bayi Lahir Dengan Kejadian Ruptur Perineum Pada Persalinan Normal di RSUD Tgk Chik Ditiro Sigli.Menurut asumsi peneliti semakin besar bayi yang lahir melalui jalan lahir ibu, maka dimungkinkan semakin besar pula robekan jalan lahir terutama robekan perineum yang akan terjadi pada saat persalinan. Berat badan bayi berpengaruh pada peregangan perineum sehingga pada perineum yang kaku mudah terjadi rupture.

Menurut Winkjosastro berat badan lahir pada janin yang berat badannya melebihi 4000 gram akan menimbulkan kesukaran persalinan, apabila dijumpa pada kepala yang besar atau kepala yang lebih keras dapat menyebabkan ruptur perineum (Kutipan Gea, 2013).

\section{KESIMPULAN}

1. Ada hubungan antara jarak kelahiran dengan kejadian rupture perineum pada persalinan normal.

2. Ada hubungan antara berat bayi lahir dengan kejadian rupture perineum pada persalinan normal.

\section{SARAN}

Hasil penelitian ini diharapkan dapat menjadi rujukan sebagai upaya bidan dalam perencanaan kesehatan ibu dan anak dalam rangka menurunkan angka kematian ibu dan bayi.

\section{DAFTAR PUSTAKA}


Journal of Healthcare Technology and Medicine Vol. 6 No. 1 April 2020

Universitas Ubudiyah Indonesia

e-ISSN : 261109X

Agoes, dkk. (2013). Mencegah dan Mengatasi Kegemukan pada Balita. Jakarta: Puspa Swara.

Ambarwati, E,R,Diah, W. (2012). Asuhan Kebidanan Nifas. Yogyakarta: Nuha Medika.

Anindhita, A., Arifputra, A., Tanto, C., Stroke. Dalam: Liwang, F. et al., eds. 2014.

APN, (2012). Buku Acuan Persalinan Normal. Jakarta: JNPK-KR

Arifputra, A., Tanto, C., Aninditha, T., Stroke. Dalam: Tanto, C. Liwang, F., dkk. (2014). Kapita Selekta Kedokteran. Jakarta: Media Aesculapius

Azwar, Saifuddin. 2010. Metode Penelitian. Yogyakarta: Pustaka Pelajar Offset.

Chalik, T.M.A. (2009). Perdarahan pada Kehamilan Lanjut dan Persalinan, Dalam: Ilmu Kebidanan, Edisi 4, Jakarta, Bina Pustaka Sarwono Prawirohardjo.

Cunningham, Gary. (2012). Obstetri Williams. Jakarta: EGC

Dewi. (2011). Asuhan Neonatus bayi dan Anak Balita. Jakarta: Salemba Medika.

Dewi, Vivian Nanny Lia. (2010). Asuhan Neonatus bayi dan Anak Balita. Jakarta: Salemba Medika.

Jannah, Nurul. (2015).Buku Ajar Asuhan Kebidanan Kehamilan. Yogyakarta: C.V Andi Offset.

Karyuni, et al. (2009). Management Handbook Problems Newborn Babies Guide for Doctors, Nurses \& Midwives . Jakarta: ECG

Kemenkes RI.(2017).Profil Kesehatan Indonesia tahun 2017. Jakarta : Kemenkes RI

Kevin P.Hanretty. (2014). Ilustrasi Obstetri. Jakarta : Nuha Medika.

Kosim, dkk. Buku Ajar Neonatologi. Jakarta: Badan Penerbit IDAI, 11-30.

Manuaba. (2010). Ilmu Kebidanan Penyakit Kandungan dan KB. Jakarta: EGC

Mitayani. (2010). Asuhan Keperawatan Maternitas. Salemba Medika Jakarta 